Check for updates

Cite this: RSC Adv., 2021, 11, 27767

\section{Facile synthesis and biological evaluation of tryptamine-piperazine-2,5-dione conjugates as anticancer agents $\uparrow$}

\author{
Jiang-Ping Meng, (D) Shi-Qiang Li, Yan Tang, Zhi-Gang Xu, Zhong-Zhu Chen \\ and Li-Xia Gao*
}

\begin{abstract}
A facile and efficient route to synthesize $\mathrm{N}$-heterocyclic fused tryptamine-piperazine-2,5-dione conjugates was developed via a post-Ugi cascade reaction. The targeted compounds were prepared by means of a mild reaction and simple operation procedure, which could be applied to a broad scope of starting materials. Compound $6 \mathrm{~h}$ was demonstrated to induce significant growth inhibition of AsPC-1 and SW1990 human pancreatic cancer cell lines $\left(\mathrm{IC}_{50}=6 \pm 0.85 \mu \mathrm{M}\right)$. Our protocol allows for the construction of a structurally diverse compound library and paves a new avenue for the discovery of pancreatic cancer drug candidates.
\end{abstract}

Received 13th May 2021

Accepted 19th July 2021

DOI: $10.1039 / \mathrm{d} 1 \mathrm{ra03740d}$

rsc.li/rsc-advances

\section{Introduction}

Multicomponent reactions (MCRs) have attracted considerable attention due to their wide application in the rapid construction of highly functionalized important chemical and biomedical heterocyclic skeletons. ${ }^{1}$ In particular, the Ugi reaction is well known as a versatile and highly efficient tool for the preparation of novel drug scaffolds from commercially available starting materials with high atom economy. ${ }^{2}$ Using alkynyls as Ugi inputs was a conventional strategy to induce new $\mathrm{C}-\mathrm{C}$ bonds during the construction of heterocycles. ${ }^{3}$ In this regard, 2-azetidinones, commonly known as $\beta$-lactams, could be constructed by $\mathrm{C}-\mathrm{C}$ bond formation employing C3 carbon in Ugi adducts with terminal or substituted alkynes (Scheme 1). ${ }^{4}$ From similar Ugi adducts, the Srivastava group reported that this reaction could occur at room temperature in the presence of NaH. ${ }^{5}$ The Van der Eycken group also published their findings that a $\gamma$-lactam core could be constructed under different conditions. ${ }^{4 b, 6}$ Besides the $\mathrm{C}-\mathrm{C}$ bond formation, the Zhang group reported a $\mathrm{C}-\mathrm{N}$ bond formation protocol to build piperazine-2,5-dione core through alkyne and amide groups (Scheme 1). ${ }^{7}$ However, the selective formation of piperazine-2,5-dione over the other $\beta$ and $\gamma$-lactams still remains challenging and deserves further exploration.

The piperazine-2,5-dione pharmacophore is presented as an important class of bioactive agents exhibiting anticancer, antibiotics and antibacterial activities. ${ }^{8}$ Therefore, a facile and economic protocol for the synthesis of new and diverse

National \& Local Joint Engineering Research Center of Targeted and Innovative Therapeutics, IATTI, College of Pharmacy, Chongqing University of Arts and Sciences, Chongqing 402160, China.E-mail: LixiaGao@cqwu.edu.cn

$\dagger$ Electronic supplementary information (ESI) available: Experimental details and spectroscopic characterization information. See DOI: 10.1039/d1ra03740d molecules bearing the piperazine-2,5-dione motif is highly demanded. The tryptamine substructure is presented in numerous naturally occurring and synthetic compounds, many of which exhibit important pharmacological activity. ${ }^{9}$ Antimigraine drugs, such as sumatriptan,${ }^{10}$ naratriptan ${ }^{11}$ and ele$\operatorname{triptan}^{12}$ have revolutionized migraine drug discovery and spurred further research for more efficient and safer treatments through activation of 5-HT1D, 5-HT1B and 5-HT1F receptors

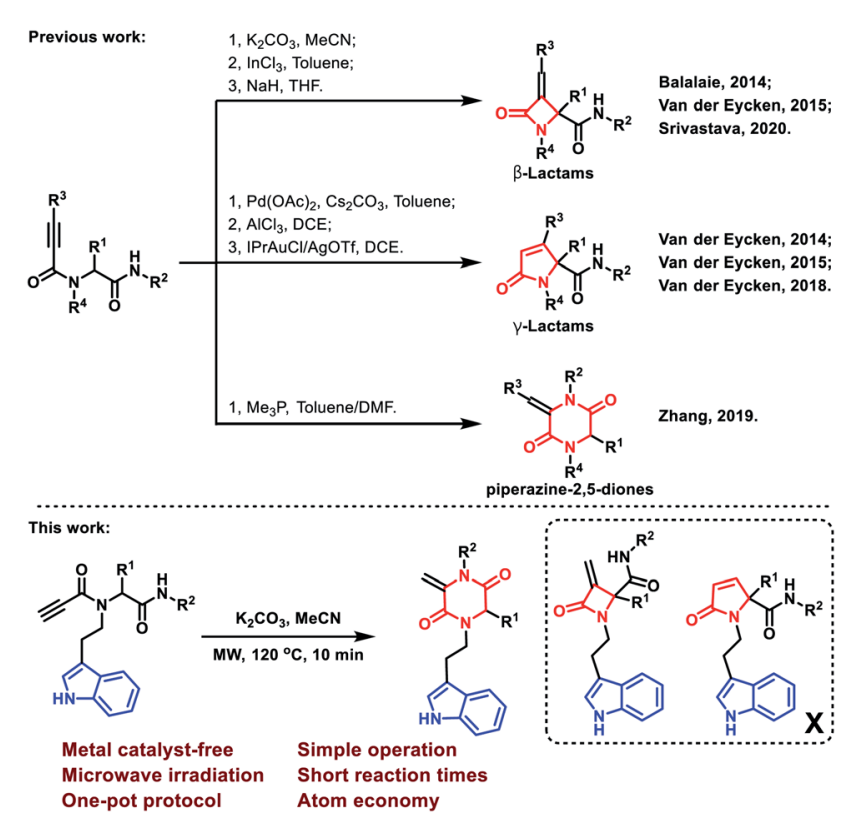

Scheme 1 Terminal and substituted alkynes to construct lactams and piperazine-2,5-diones. 
Table 1 Optimization for the synthesis of compound $6 a^{a}$

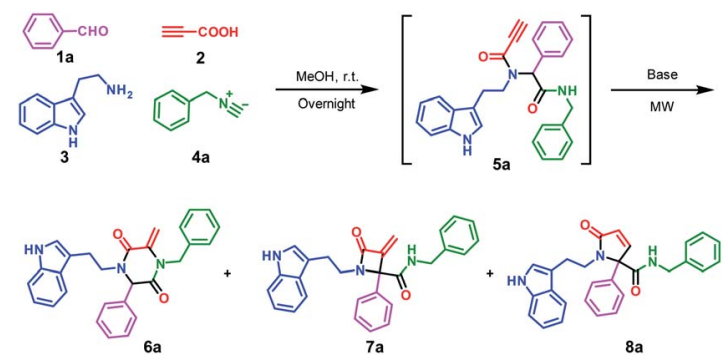

\begin{tabular}{|c|c|c|c|c|c|c|c|}
\hline \multirow[b]{2}{*}{ Entry } & \multirow[b]{2}{*}{ Base } & \multirow[b]{2}{*}{ Solvt. } & \multirow[b]{2}{*}{ Temp. $\left({ }^{\circ} \mathrm{C}\right)$} & \multirow[b]{2}{*}{ Time (min) } & \multicolumn{3}{|c|}{ Yield (\%) } \\
\hline & & & & & $6 a^{b}$ & $7 \mathbf{a}^{b}$ & $8 a^{b}$ \\
\hline 1 & $\mathrm{Cs}_{2} \mathrm{CO}_{3}$ & $\mathrm{MeCN}$ & r.t. & 120 & 5 & Trace & Trac \\
\hline 2 & $\mathrm{Cs}_{2} \mathrm{CO}_{3}$ & $\mathrm{MeCN}$ & MW 80 & 10 & 30 & Trace & Trac \\
\hline 3 & $\mathrm{Cs}_{2} \mathrm{CO}_{3}$ & $\mathrm{MeOH}$ & MW 80 & 10 & 19 & 10 & 0 \\
\hline 4 & $\mathrm{Cs}_{2} \mathrm{CO}_{3}$ & EtOH & MW 80 & 10 & 26 & $<5$ & 0 \\
\hline 5 & $\mathrm{Cs}_{2} \mathrm{CO}_{3}$ & DCE & MW 80 & 10 & 11 & 10 & 0 \\
\hline 6 & $\mathrm{Cs}_{2} \mathrm{CO}_{3}$ & Dioxane & MW 80 & 10 & 15 & 0 & 0 \\
\hline 7 & $\mathrm{Cs}_{2} \mathrm{CO}_{3}$ & DMF & MW 80 & 10 & $<10$ & Trace & 0 \\
\hline 8 & ${ }^{t} \mathrm{BuONa}$ & $\mathrm{MeCN}$ & MW 80 & 10 & 41 & 10 & 0 \\
\hline 9 & $\mathrm{NaOH}$ & $\mathrm{MeCN}$ & MW 80 & 10 & 36 & 0 & 0 \\
\hline 10 & DABCO & $\mathrm{MeCN}$ & MW 80 & 10 & 21 & $<5$ & 0 \\
\hline 11 & DIPEA & MeCN & MW 80 & 10 & 0 & $<5$ & $<5$ \\
\hline 12 & DIPA & $\mathrm{MeCN}$ & MW 80 & 10 & 0 & Trace & $<5$ \\
\hline 13 & $\mathrm{Et}_{3} \mathrm{~N}$ & $\mathrm{MeCN}$ & MW 80 & 10 & 10 & 0 & 0 \\
\hline 14 & $\mathrm{~K}_{2} \mathrm{CO}_{3}$ & $\mathrm{MeCN}$ & MW 80 & 10 & 46 & 0 & 0 \\
\hline 15 & $\mathrm{~K}_{2} \mathrm{CO}_{3}$ & DMF & MW 80 & 10 & 23 & 0 & $<5$ \\
\hline 16 & $\mathrm{~K}_{2} \mathrm{CO}_{3}$ & $\mathrm{MeCN}$ & MW 90 & 10 & 50 & 0 & 0 \\
\hline 17 & $\mathrm{~K}_{2} \mathrm{CO}_{3}$ & MeCN & MW 100 & 10 & 53 & 0 & 0 \\
\hline 18 & $\mathrm{~K}_{2} \mathrm{CO}_{3}$ & MeCN & MW 110 & 10 & 71 & 0 & 0 \\
\hline 19 & $\mathrm{~K}_{2} \mathrm{CO}_{3}$ & MeCN & MW 120 & 10 & 92 & $\mathbf{0}$ & $\mathbf{0}$ \\
\hline 20 & $\mathrm{~K}_{2} \mathrm{CO}_{3}$ & MeCN & MW 130 & 10 & 83 & 0 & 0 \\
\hline 21 & $\mathrm{~K}_{2} \mathrm{CO}_{3}$ & $\mathrm{MeCN}$ & MW 120 & 20 & 82 & 0 & 0 \\
\hline
\end{tabular}

${ }^{a}$ Reaction conditions: $\mathbf{5 a}(0.3 \mathrm{mmol})$ and bases $(2.0 \mathrm{eq}$.) in solvent $(2.0$ $\mathrm{mL}) . \mathrm{MW}=$ microwave irradiation. ${ }^{b}$ Isolated yields. $\mathrm{DABCO}=1,4$ diazabicyclo[2.2.2] octane; DIPEA $=N, N$-diisopropylethylamine; DIPA $=$ diisopropanolamine.

with high affinities. ${ }^{13}$ In continuation of our endeavor towards the development of diversity-oriented synthesis of heterocyclic scaffolds through post-Ugi modifications, ${ }^{14}$ we envisioned the synthesis of tryptamine-piperazine-2,5-diones could be achieved by an Ugi cascade cyclization. To the best of our knowledge, no tryptamine-piperazine-2,5-diones have been reported as anticancer agents so far; therefore, our findings lay the foundation for the discovery and development of substituted tryptamines in cancer research. Herein, we report a post-Ugi base-catalyzed intramolecular nucleophilic cyclization for the synthesis of tryptamine-piperazine-2,5-diones for cancer treatment. As anticipated, the representative compound showed excellent selectivity and potent anti-proliferative activity against AsPC-1 and SW1990 human pancreatic cancer cell lines. ${ }^{15}$

\section{Results and discussion}

To investigate the potential of post-Ugi cyclization reactions for the construction of heterocycles, a highly functionalized precursor 5a was readily constructed through the Ugi fourcomponent reaction from benzaldehyde 1a, propiolic acid 2, tryptamine 3 and benzyl isocyanide $4 \mathbf{a}$ (Scheme 1). The Ugi reaction proceeded in methanol at room temperature in high yield, so we focused on the reaction condition optimization of the subsequent cyclization of $\mathbf{5 a}$.

We screened various inorganic and organic bases in terms of their ability to promote the nucleophilic $\alpha$-addition of amides (Table 1, entries 1-9). To our delight, ${ }^{t} \mathrm{BuONa}$ and $\mathrm{NaOH}$ allowed for the successful transformation from $5 \mathbf{a}$ to $\mathbf{6 a}$ in over $30 \%$ isolated yield; but in organic base systems, the targeted compound 6a was found in lower yields and compound $7 \mathbf{a}$ and 8a could be found from LC/MS analysis (entries 10-12). Interestingly, when $\mathrm{K}_{2} \mathrm{CO}_{3}$ was used, good to excellent yields were observed for the target product 6a. Particularly, when 5a was irradiated under microwave at $120^{\circ} \mathrm{C}$ for $10 \mathrm{~min}$ in the presence of 2.0 equiv. of $\mathrm{K}_{2} \mathrm{CO}_{3}$, 6 a was obtained in $92 \%$ yield (entry 19 ). Elevated reaction temperature or prolonged reaction time both

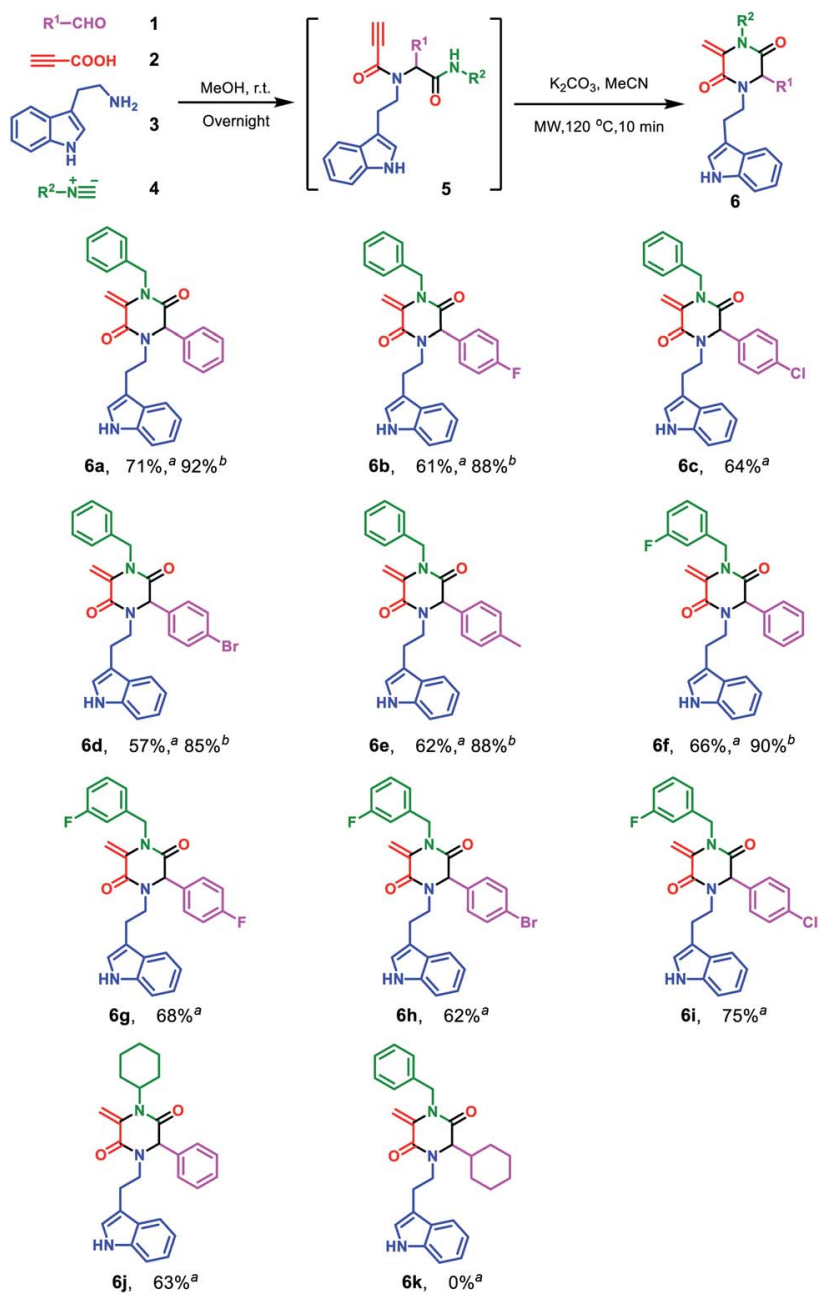

Scheme 2 Scope of the Ugi cascade route leading to tryptaminepiperazine-2,5-diones 6a-j. Reaction conditions: 1 (1.0 mmol), 2 (1.0 $\mathrm{mmol}), 3(1.0 \mathrm{mmol})$ and $4(1.0 \mathrm{mmol})$ in $\mathrm{MeOH}(2.0 \mathrm{~mL})$ under air; After workup, added $\mathrm{K}_{2} \mathrm{CO}_{3}(2.0 \mathrm{mmol})$ in $\mathrm{MeCN}(3.0 \mathrm{~mL})$, microwave irradiation in a sealed tube at $120{ }^{\circ} \mathrm{C}$, for $10 \mathrm{~min}$. ${ }^{a}$ Isolated yields with onepot two-step protocol; ' Isolated yields of only cyclization step. 
diminished the product yield (entries 20 and 21). With the wellestablished reaction condition in hand, we turned our attention to further exploration instead of trying other conditions, including Me3P. ${ }^{7}$

Encouraged by the excellent yield of $6 \mathbf{a}$, we envisioned that crude 5a could be directly subjected to the cyclization reaction without further purification. To verify our hypothesis, the Ugi reaction solvent was removed under a gentle stream of nitrogen to give crude 5a, which was confirmed by LC/MS. Then, crude 5a was dissolved in MeCN and treated in microwave irradiation under basic conditions. This two-step one-pot cascade reaction delivered $\mathbf{6 a}$ in $71 \%$ yield. Then, we investigated the scope of this cyclization reaction by varying starting materials (Scheme 2). In all cases, initial Ugi products $\mathbf{5 a}-\mathbf{j}$ were obtained in good yields; after removal of the reaction solvent, $\mathbf{5 a}-\mathbf{j}$ were used directly without purification to give tryptamine-piperazine-2,5diones $\mathbf{6 a - j}$ in $57-75 \%$ yields. Aromatic aldehyde bearing electron donating or withdrawing groups were all well tolerated; however, primary aliphatic aldehyde couldn't give the corresponding product 6k. Due to the limited source of tryptamines, only 2 -(1H-indol-3-yl)ethan-1-amine 3 was tested and this unprotected indole group still provided the Ugi product in good yields. It is noteworthy that although the Ugi adduct 5 was not purified by column chromatography, the usage of the crude product has no discernible impact on the overall yield. In comparison with Balalaie's method ${ }^{4 a}$ for the construction of $\beta$ lactams, the only difference is alkyl amines in our method instead of aromatic amines in the Ugi inputs. The electrowithdraw substituents of aromatic amine in the Ugi skeletons would promote the intramolecular nucleophilic addition of carbanion to a triple bond to form the $\beta$-lactam skeleton. However, in our reaction system, alkyl tryptamine group would perform the intramolecular nucleophilic $\alpha$-addition to form the piperazine-2,5-dione ring. In addition, metal catalysts are needed to activate terminal alkynes, which is why only trace of pyrrolidine-2,5-dione 8a was found by LC/MS.

To evaluate the potential to develop a drug candidate from the synthesized compounds, a thymidine incorporation assay was used to measure cancer cell viability upon drug treatments at the concentration of $20 \mu \mathrm{M}$. Totally 10 cancer cell lines, including MHCC97H, MHCC97L, MDA-MB-231, MCF-7, UM1, Cal-27, HCT116, SW620, AsPC-1 and HPAC, were selected for initial screening (see ESI $\dagger$ for details), which are some of the difficult-to-inhibit cell lines in the National Cancer Institute's 60 human tumour cell lines panel. ${ }^{\mathbf{1 6}}$ Interestingly, we found that $\mathbf{6 h}$ has selective inhibitory activities on pancreatic cancer cell lines AsPC-1 and HPAC (Fig. 1A and S1 $\dagger$ ). The results verified our assumption and proved that the tryptamine-piperazine-2,5-dione 6 could be a starting point towards the discovery of potent anticancer drugs. The compound $\mathbf{6 h}$ has not cytotoxic to normal pancreatic duct cells at $6 \mu \mathrm{M}$ (Fig. S2 $\dagger$ ). In addition, 6h showed excellent drug activity compared with clinical drugs for pancreatic cancer (Fig. S3 $\dagger$ ). Compound $\mathbf{6 h}$, bearing a bromo group at the para-position of phenyl ring, showed better potency than the chloro analogue $\mathbf{6 i}$. However, compound $\mathbf{6 d}$, lacking a fluoro group on the isocyanide starting material, exhibited much lower antiproliferative activity. Taken together, these results further proved that substitution groups of aromatic ring of the aldehyde and the substituents of benzyl group played key roles in altering the compounds inhibitory potency against pancreatic cancer cells. The information of structure-activity relationships (SAR) provided us a guideline to improve the compounds anticancer activity in the future during structural modification.
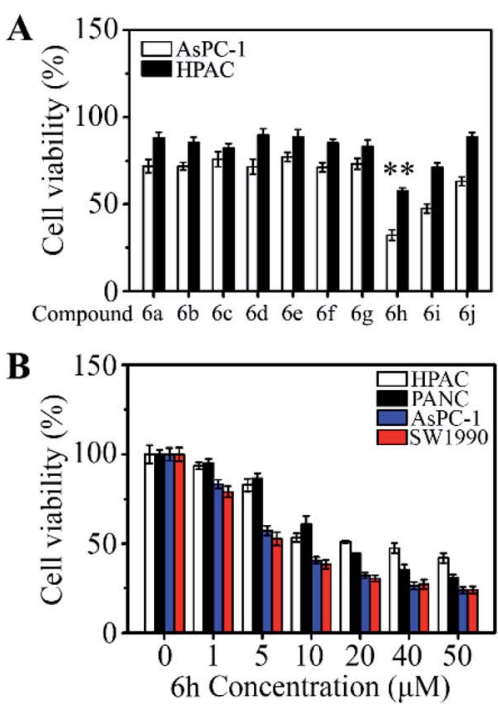
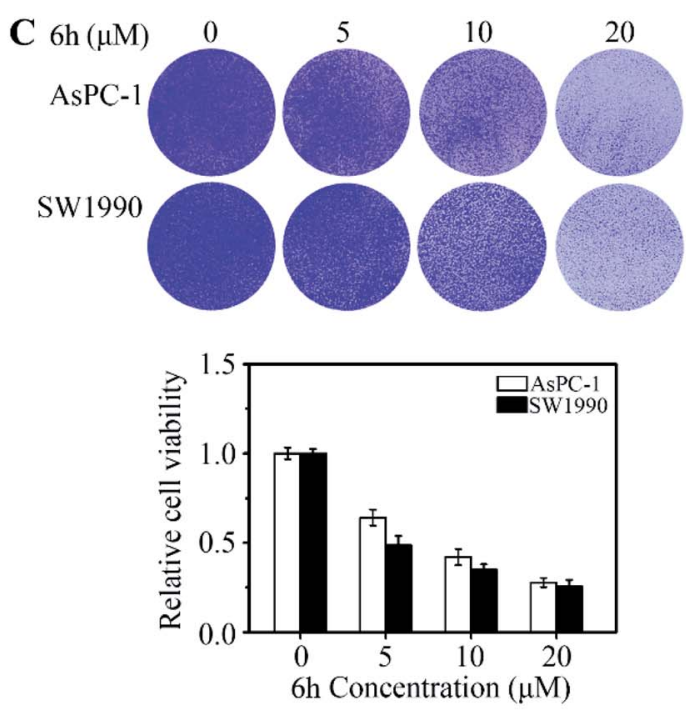

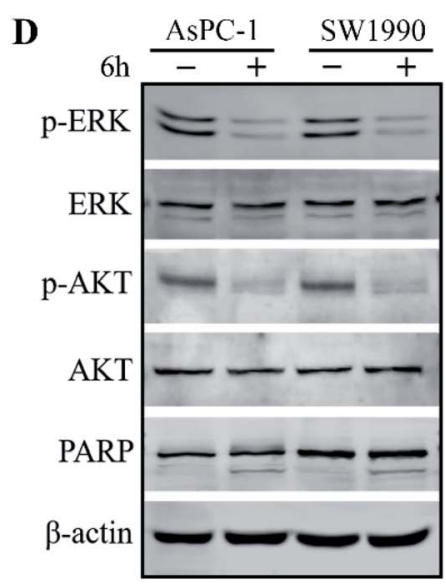

Fig. $16 \mathrm{~h}$ inhibits cell viability and induces apoptosis in pancreatic cancer cells. (A and B) The effect of compounds $6 a-j$ on cell viability in pancreatic cancer cell lines. In (A), AsPC-1 and HPAC cells were treated with the $20 \mu \mathrm{M}$ concentrations of $6 a-j$ for 48 hours, and cell viability was detected by MTT assays. In (B), $5 \times 10^{3}$ AsPC-1, PANC-1, SW1990 and PANC-1 cells were seeded into 96 -well-plates and treated with $6 \mu$ M $6 \mathrm{~h}$ DMSO for 48 hours, In (C), AsPC-1 and SW1990 cells were determined the growth ability. AsPC-1 and SW1990 cells were treated with $6 \mu$ M $6 \mathrm{~h}$ for 48 hours, and the viability cells were staining by crystal violet. The crystal violet staining pictures are shown in the up panel and quantitative data are shown in the down panel. In (D), western blot assay detected the cell proliferation and apoptosis protein expression $* p<0.05 ; * p<0.01$. 
To determine the effective dose range of $\mathbf{6 h}$, four cell lines, AsPC-1, PANC-1, SW1990 and HPAC, were treated with $\mathbf{6 h}$ at drug concentrations from $1 \mu \mathrm{M}$ to $50 \mu \mathrm{M}$ for 48 hours. These results indicated that pancreatic cancer cells have different sensitivity to 6h. We selected two cells (AsPC-1, SW1990) that were more sensitive to $\mathbf{6 h}$ for subsequent experiments (Fig. 1B). Compound $\mathbf{6 h}$ exhibited dose-dependent anticancer activities and selectivity in AsPC-1 and HPAC cell lines with an $\mathrm{IC}_{50}=6 \pm$ $0.85 \mu \mathrm{M}$. These data were in line with the cell growth assays data when AsPC-1 and SW1990 cells were treated with $\mathbf{6 h}$ at different drug concentrations (Fig. 1C). We next determined cell growth inhibition rate with western blot at $6 \mu \mathrm{M}$ of $\mathbf{6 h}$. Oncogenic ERK and AKT phosphorylation were significantly suppressed upon drug treatment for $48 \mathrm{~h}$ and these results suggested that $\mathbf{6 h}$ induced AsPC-1 and SW1990 cell apoptosis (Fig. 1D). To study the possible mechanisms that induced cell death, we examined the expression of apoptosis-related protein in the presence or absence of 6h. A significantly increased apoptotic rate was found following $\mathbf{6 h}$ exposure (Fig. 1D), which was accompanied by increased levels of cleaved PARP. These data proved that compound $\mathbf{6 h}$ can inhibit human pancreatic cell proliferation and induce cell apoptosis.

\section{Conclusion}

In conclusion, a series of tryptamine-piperazine-2,5-dione derivatives was designed and synthesized via Ugi cascade reaction. Microwave-assisted synthesis protocol delivered target compounds in high purity and excellent yield. The nonlinear SAR studies showed that the substitution groups of aldehyde and benzyl group in isocyanide played vital roles in altering the compounds inhibitory potency against pancreatic cancer cells. Furthermore, 6h significantly decreased the phosphorylation of oncogenic proteins ERK and AKT; and meanwhile increased levels of cleaved PARP in AsPC-1 and SW1990 cells. Exemplified by compound 6h, our work presented in this paper paved a new avenue for the discovery of pancreatic cancer drug.

\section{Conflicts of interest}

The authors declare no competing financial interest.

\section{Acknowledgements}

The authors would like to thank the Science and Technology Research Program of Chongqing Municipal Education Commission (KJQN202001347 and KJZD-M201801301) and the Natural Science Foundation Project of CQ CSTSC (cstc2019jcyjmsxmX0012, cstc2019jcyj-msxmX0202, cstc2020jcyjmsxmX0733 and cstc2018jszx-cyzdX0023). We would also like to thank Ms H. Z. Liu and J. Xu for obtaining the LC/MS, HRMS and NMR data.

\section{Notes and references}

1 For selected reviews, see: (a) A. Dömling and I. Ugi, Angew. Chem., Int. Ed., 2000, 39, 3168-3210; (b) G. R. Kuethe,
Chem. Rev., 2006, 106, 2875-2911; (c) A. Dömling, W. Wang and K. Wang, Chem. Rev., 2012, 112, 3083-3135; (d) T. Vlaar, B. U. Maes, E. Ruijter and R. V. Orru, Angew. Chem., Int. Ed., 2013, 52, 7084-7097; (e) B. H. Rotstein, S. Zaretsky, V. Rai and A. K. Yudin, Chem. Rev., 2014, 114, 8323-8359; $(f)$ S. Brauch, S. S. Van Berkel and B. Westermann, Chem. Soc. Rev., 2013, 42, 4948-4962.

2 (a) W. Zhang, Green Chem., 2009, 11, 911-920; (b) A. Singh and A. Kumar, RSC Adv., 2015, 5, 2994-3004; (c) L. Banfi, A. Basso, C. Chiappe, F. De Moliner, R. Riva and L. Sonaglia, Org. Biomol. Chem., 2012, 10, 3819-3829.

3 (a) Z. Xu, F. De Moliner, A. P. Cappelli and C. Hulme, Angew. Chem., Int. Ed., 2012, 51, 8037-8040; (b) W. Liao, S. Li, J. Wang, Z. Zhang, Z. Yang, D. Xu, C. Xu, H. Lan, Z. Chen and Z. Xu, ACS Comb. Sci., 2016, 18, 65-69.

4 (a) E. Ghabraie, S. Balalaie, S. Mehrparvar and F. Rominger, J. Org. Chem., 2014, 79, 7926-7934; (b) Z. Li, U. K. Sharma, Z. Liu, N. Sharma, J. N. Harvey and E. V. Van der Eycken, Eur. J. Org. Chem., 2015, 2015, 3957-3962.

5 S. P. Singh, S. Tripathi, A. Yadav, R. Kant, H. K. Srivastava and A. K. Srivastava, Chem. Commun., 2020, 56, 12789-12792.

6 (a) N. Sharma, Z. Li, U. K. Sharma and E. V. Van der Eycken, Org. Lett., 2014, 16, 3884-3887; (b) Z. Li, L. Song, L. Van Meervelt, G. Tian and E. V. Van der Eycken, ACS Catal., 2018, 8, 6388-6393; (c) C. Liu, G. Wang, Y. Wang, K. Van Hecke, O. P. Pereshivko and V. A. Peshkov, Tetrahedron Lett., 2018, 59, 1823-1827.

7 Y.-K. Xi, H. Zhang, R.-X. Li, S.-Y. Kang, J. Li and Y. Li, Chem.Eur. J., 2019, 25, 3005-3009.

8 (a) Z. Fu, Y. Hou, C. Ji, M. Ma, Z. Tian, M. Deng, L. Zhong, Y. Chua and W. Li, Bioorg. Med. Chem., 2018, 26, 20612072; (b) S. Liao, X. Qin, D. Li, Z. Tu, J. Li, X. Zhou, J. Wang, B. Yang, X. Lin, J. Liu, X. Yang and Y. Liu, Eur. J. Med. Chem., 2014, 83, 236-244; (c) D. Kumar, S. K. Gupta, A. Ganeshpurkar, G. Gutti, S. Krishnamurthy, G. Modi and S. K. Singh, Eur. J. Med. Chem., 2018, 150, 87-101; (d) M. Luo, G. Tang, J. Ju, L. Lu and H. Huang, Nat. Prod. Res., 2016, 30, 138-143.

9 (a) I. Sosič, M. Anderluh, M. Sova, M. Gobec, I. Mlinarič Raščan, A. Derouaux, A. Amoroso, M. Terrak, E. Breukink and S. Gobec, J. Med. Chem., 2015, 58, 9712-9721; (b) B. M. Trost, W.-J. Bai, C. Hohn, Y. Bai and J. J. Cregg, J. Am. Chem. Soc., 2018, 140, 6710-6717; (c) M. Ishikura, T. Abe, T. Choshi and S. Hibino, Nat. Prod. Rep., 2015, 32, 1389-1471.

10 Z. Wojnarowska, J. Knapik, M. Rams-Baron, A. Jedrzejowska, M. Paczkowska, A. Krause, J. Cielecka-Piontek, M. Jaworska, P. Lodowski and M. Paluch, Mol. Pharmaceutics, 2016, 13, 1111-1122.

11 H. E. Connor, W. Feniuk, D. T. Beattie, P. C. North, A. W. Oxford, D. A. Saynor and P. P. Humphrey, Cephalalgia, 1997, 17, 145-152.

12 M. Capi, M. Curto, L. Lionetto, F. de Andrés, G. Gentile, A. Negro and P. Martelletti, Ther. Adv. Neurol. Disord., 2016, 9, 414-423.

13 P. J. Goadsby, Mol. Diagn. Ther., 1998, 10, 271-286. 
14 (a) G.-T. Song, N. McConnell, Z.-Z. Chen, X.-F. Yao, J.-H. Huang, J. Lei, H.-K. Lin, H. Li and Z.-G. Xu, Adv. Synth. Catal., 2018, 360, 3655-3661; (b) Z.-Z. Chen, S.-Q. Li, Y.-J. Zhang, D.-Y. Tang, J.-P. Meng, J. Lei, H. Li and Z.-G. Xu, Org. Lett., 2018, 20, 7811-7815; (c) J. Lei, Y. Li, L.-J. He, Y.-F. Luo, D.-Y. Tang, W. Yan, H.-K. Lin, H. Li, Z.-Z. Chen and Z.-G. Xu, Org. Chem. Front., 2020, 7, 987992; (d) J. Lei, Y. Li, J. Xu, D.-Y. Tang, J.-W. Shao, H. Li, Z.-Z. Chen and Z.-G. Xu, Green Chem., 2020, 22, 3716-3720.

15 (a) L. Gummidi, N. Kerru, P. Awolade, A. Raza, A. K. Sharma and P. Singh, Bioorg. Med. Chem. Lett., 2020, 30, 127544; (b) J. S. Kumar, B. Thirupataiah, R. Medishetti, A. Ray, S. D. Bele, K. A. Hossain, G. S. Reddy, R. K. Edwin, A. Joseph, N. Kumar, G. G. Shenoy, C. M. Rao and M. Pal, Eur. J. Med. Chem., 2020,
201, 112335; (c) J. S. Kumar, G. S. Reddy, R. Medishetti, A. Ray, S. D. Bele, K. A. Hossain, B. Thirupataiah, R. K. Edwin, P. Behera, A. Joseph, G. G. Shenoy, C. M. Rao and M. Pal, J. Mol. Struct., 2021, 1240, 130534; (d) S. Cascioferro, G. Li Petri, B. Parrino, B. El Hassouni, D. Carbone, V. Arizza, U. Perricone, A. Padova, N. Funel, G. J. Peters, G. Cirrincione, E. Giovannetti and P. Diana, Molecules, 2020, 25, 329; (e) X. Qin and X. Cui, 3 Biotech, 2020, 10, 187.

16 (a) N. A. Shafakat Ali, B. Ahmad Dar, V. Pradhan and M. Farooqui, Mini-Rev. Med. Chem., 2013, 13, 1792-1800; (b) J. Xu, H.-B. Tan, Y.-J. Zhang, D.-Y. Tang, F. Zhan, H. Li, Z.-Z. Chen and Z.-G. Xu, Sci. Rep., 2020, 10, 9281. 